\section{A LETTER TO THE EDITOR}

July 3, 1995

Microscopy Today

PO BOX 122

Middleton, WI 53562

Dear Mr. Grimes

I received my copy of Cell and Tissue

Ultrastructure, a Functional Perspective

last Friday. It's great! As I am

certain that one of our students will

'borrow' it, I must have another copy

for my personal use. Enclosed is my

- check for $\$ 49.00$. Please send to me as

follows.

Thank you,

s/Dian V. Molsen

Department of Biological Sciences

Montgomery Hall

Northern Illinois University

DeKalb, IL 60115

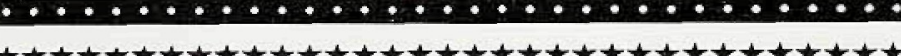

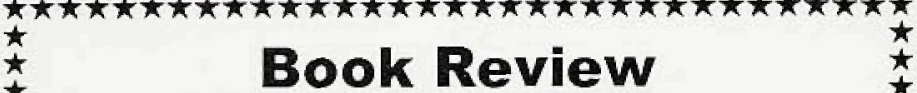
The Microwave Tool Book

The Microwave Tool Book is an interactive teaching $\star$ guicle for slinical laboratory and research personnel. Most laboratory personnel are familiar with the advantages of $\star$ microwave technology (e.g. increased reaction speed); however. implementation of microwave methods has been $\star$ slow because of the inherent variability of all domestic and laboratory microwave ovens. The Microwave Tool $\star$ Book is a necessary companion to other books and articles on microwave methods because it is the only book $\star$ available which shows how to adapt published procedures $\hbar$ to your microw ave equipment. It specifically teaches how $\star \star$ to calibrate and standardize a microwave oven for $\star$ accelerating tissue fixation, resin curing, and staining for light and electron microscopy.

The Microwave Tool Book teaches the reader how to $\star$ build and use simple and inexpensive tools to visualize $\star$ the hot and 'cold' spots in a microwave oven. identify $\star$ areas of uniform irradiation, measure temperature * accurately, and select appropriate containers for $\star$ $\star$ consistently good results in any microwave oven. $\star$ Excellent diagrams, a list of key learning points, and $\star \star$ $\star$ safely guidelines accompany each laboratory exercise. $\star$ * The Microwave Tool Book is also an ideal teaching aid for $\star$ thigh school and college students and for use at $\star$ conferences because several of its exercises can be used * lor visually exciting demonstrations of important $\star$ $\star$ principles of microwave oven function.

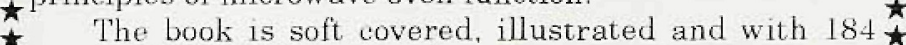
pages. The ISBN number is $0-9642675-0-0$. The price is $\star$ $\$ 60.00$ and may be ordered from

Beth Israel Hospital

Department of Pathology \#45110

330 Brookline Avenue

Boston, MA 02215

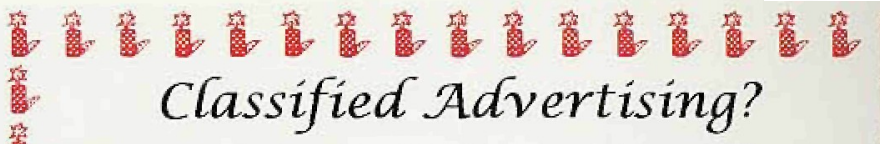

Due to space limitations, readers will note a lack of classified advertising in this issue.

In our next issue, we will run advertising for equioment either for sale or wanted at no charge. If interested, submit your concise adver twing text to us prior to 25 August - by fax or by eMait.

If you will provide us with the name and address of the individual in your organization responsible for purchasing or selling used equipment, we will see that he/she gets a copy!

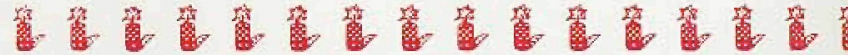 \\ Why A Clean Vacuum Is Not The Same As A High Vacuum}

Ronald Vane, XEI Scientific

Most conventional electron microscopes operate in the high vacuum region. The term "high vacuum" refers to an absolute total pressure in the vacuum chamber in the $10^{-5}$ to $10^{-8}$ Torr range. A clean vacuum refers to a low partial pressure $\left(<10^{-8} \mathrm{Torr}\right)$ of undesirable molecules in the system. In electron microscopes a clean vacuum, in general, refers to a low partial pressure of hydrocarbons, silicones, and certain other dirt. These are the materials which interact in a negative way with the electron bearn to produce bad pictures. The electron beam is not bothered very much by the normal components of air - nitrogen, oxygen and water vapor in the specimen chamber. Because of this fact, the specimen chambers of most common microscopes operate in the $10^{-5}$ to $10^{-7}$ Torr region. $10^{-7}$ Torr is about the lower limit of vacuum in an SEM chamber due to system design and water vapor outgasing.

For hydrocarbons the electron beam is more sensitive. Hydrocarbons interact with the electron beam to produce positive ions which collect on the negatively charged rastered surface to produce a carbon polymer. The carbon appears as a black spot on the sample because low Z materials have a low yield of secondary electrons. Thus we get raster burns from contamination in our pictures. Common roughing pump oils have a vapor pressure of about $10^{-7}$ Torr. This translates into 1 in every 10 molecules encountered by the electron beam at $10^{-6}$ Tor - plenty of molecules for ionization. And there is more - the majority of the oil and other gases in the chamber reside on the chamber walls rather than in the gas phase. To have a clean vacuum these oils and other dirt must be removed from the chamber.

To achieve ultra-high vacuums, the classic technique is to bake the chamber to force all of the extra gas molecules off the walls and into the pumps. Baking is needed to achieve ultra-high vacuums of $10^{-8}$ and better. Ultrahigh vacuums are clean vacuums because the partial pressures of the oils and contaminants are also less than $10^{-8}$ Torr.

Can we have a clean vacuum without an ultrahigh vacuum and baking? Yes, just selectively remove the hydrocarbons from the walls and replace them with friendly molecules. This can be done by solvent cleaning of the chamber or by purging, under vacuum, by an inert gas such as nitrogen which carries away the contaminants under viscous flow conditions. The low vacuum environmental SEMs which feature high flow differential pumping are not susceptible to contamination because of this effect. Even though they operate at relatively high pressures they have clean vacuums because the partial pressure of contaminants is low. They are low because the contaminants on the walls are not in equilibrium with the clean, flowing gas. A nitrogen purge will also remove contaminants from the chamber - producing a clean vacuum. Purging can either be done with a continuous flow or with cycling by partially venting the chamber with a clean gas and reevacuating several times in succession. The longer purging is done, the more contaminants will be captured from the walls and removed from the chamber. 